American Journal of Applied Sciences 7 (4): 556-561, 2010

ISSN 1546-9239

(C) 2010Science Publications

\title{
A Survey on Environmental Factors and Job Satisfaction Among Operators in Automotive Industry
}

\author{
${ }^{1}$ A.R. Ismail, ${ }^{2}$ M.H.M. Haniff, ${ }^{2}$ C.B. Kim, ${ }^{2}$ B.M. Deros and ${ }^{2}$ N.K. Makhtar \\ ${ }^{1}$ Faculty of Mechanical Engineering, University Malaysia Pahang, \\ 26600 Pekan, Pahang, Malaysia \\ ${ }^{2}$ Department of Mechanical and Materials Engineering, \\ Faculty of Engineering and Built Environment, \\ University Kebangsaan Malaysia, 43600 UKM Bangi, Malaysia
}

\begin{abstract}
Problem statement: A survey was conducted to investigate the relationship between environmental factors, job satisfaction that influence the workers' discomfort in four automotive manufacturing in Malaysia. Discomfort level of operator in workstation often were associated with workstation design, posture comfort operator at work, activity which involved work and place influence environment such as heat, noise and lighting. The aim of this study was to assess discomfort level based on ergonomic factors and to determine the distribution of body discomfort in relation to the task performed. Approach: Identification of discomfort level among the operators was carried out in four automotive companies in Malaysia. The study was carried out based on questionnaire responses from the participating factories and the collected data was analyzed through the SPSS software. Results: In the analysis data, research showed left arm was part of the body most involved a lot of activity like activity lifting, pulling, twisting, carrying and holding. Conclusion: The study revealed that the dominant factors contribute to the productivity at the body assembly production line is WBGT and I luminance whereas the empirical finding was closely related to the perception study by survey questionnaire distribution.
\end{abstract}

Key words: Musculoskeletal, heat, noise, lighting, productivity

\section{INTRODUCTION}

The goal of ergonomics is to ensure a good fit between the workers and their job, thereby maximizing worker's comfort, safety and health, productivity and efficiency (Mustafa et al., 2009). Workstation design from an ergonomics perspective can effectively enhance productivity and minimize stress through the interaction between the various system components (Dempsey et al., 2004). An optimum workstation design that can keep the operator comfortable must provide adequate postural support, proper distribution of body/limb weight, natural body/limb positions and should require little demand to use maximum reach or force. Most of the time, the user acceptance and operator motivation are the main psychological objectives of an industrial workplace layout and they can be achieved if the workplace is simple, convenient, well organized, attractive, reliable and safe (Das and Grady, 1983). According to (De Croon et al., 2005), the work station design may directly or indirectly result in physiological and psychological reactions such as crowding stress (psychological state of inadequacy of space), occupationally induced fatigue, job satisfaction decrement and increased levels of blood pressure. In addition, the long term reactions include decreased performance and negative health outcomes, such as psychosomatic health complaints including chronic fatigue, burnout and musculoskeletal disorders (De Lange et al., 2002: Sluiter et al., 2003). Workplace dimensions should be compatible with the anthropometric characteristics of the anticipated user. The following operator related dimensional factors that influence industrial workplace layout should be considered is postural control and distribution of body weight, reach envelope of hands and eye position with regard to display area (Das and Grady, 1983).

Job satisfaction has been defined as a pleasurable emotional state resulting from the appraisal of one's job or an affective reaction to one's job and an attitude

Corresponding Author: A.R. Ismail, Faculty of Mechanical Engineering, University Malaysia Pahang, 26300 UMP, Kuantan, Pahang, Malaysia 
towards one's job. This positive feeling is customary revenue from perception one job that can fulfill someone else deep or important position achievement in certain field, if these factors are compatible some with the need. These factors are customary referring to each want or somebody achievement where job satisfaction could be regarded as consideration of work level about the job those related with the remuneration (Locke, 1976).

Matzler and Renzl (2006) prepared the questionnaire included questions concerning employee satisfaction within the nine different work satisfaction areas to test hypotheses. In the questionnaire, each of the different employee satisfaction areas was measured by at least two standardized statements using a 5-point rating scale (from $1 \frac{1 / 4}{4}$ very satisfied to $5 \frac{1 / 4}{4}$ very dissatisfied). Overall employee satisfaction was measured using a 100 percent scale. Both these selected areas and the item-variables used were derived from well developed and empirically tested scales to measure employee satisfaction proposed in literature.

Employee satisfaction is a central concern in the service industry in general and in hospitality and tourism in particular. Employee satisfaction is typically viewed as a multi-factorial construct, assuming that some satisfaction factors are more important than others (Matzler and Renzl, 2006). Several researchers have discover the problems in the workstations which are poor workstation design, mix-up of tested and untested boards, missing or incorrect test steps and unclear pass/fail color inspection criteria (Yeow and Sen, 2003 ). Besides, (Hoy et al., 2005) also clarify a worker friendly workplace can generate short term advantages such as cost reduction and productivity improvement as well as long term benefits from increased employee motivation and reduced staff turnover, reduced absence due to sickness and reduced insurance costs. Besides that, consideration also must give to environmental factors such as illumination, temperature, ventilation, noise and vibration.

From the (Parsons, 2000) study, a review of the principles, methods and models used in environmental ergonomics is provided in terms of the effects of heat and cold, vibration, noise and light on the health, comfort and performance of people. Environmental ergonomics is an integral part of the discipline of ergonomics and should be viewed and practiced from that perspective. Humans do not respond to the environment in a way monotonically related to direct measures of the physical environment. There are human characteristics which determine human sensitivities and responses. Practical methods for assessing responses to individual environmental components are presented as well as responses to 'total' environments and current and proposed International Standards concerned with the ergonomics of the physical environment.

According to the Fisk and Rosenfeld (1997) productivity was one of the most important factors affecting the overall performance to any organization, from small enterprises to entire nations (Fisk and Rosenfeld, 1997). Increased attention had focused on the relationship between the work environment and productivity since the 1990s. Laboratory and field studies showed that the physical and chemical factors in the work environment could have a notable impact on the health and performance of the occupants and consequently on the productivity. Workplace environmental conditions, such as humidity, indoor air quality and acoustics have significant relationships with workers' satisfaction and performance (Tarcan et al., 2004; Marshall et al., 2002). Indoor air quality could have a direct impact on health problems and leads to uncomfortable workplace environments (Czubaj, 2002).

Previous research done by (Ettner and Grzywacz, 2001) showed that the work environments were associated with perceived effects of work on health. This research used a national sample of 2,048 workers who were asked to rate the impact of their respective jobs job on their physical and mental health. Regression analyses proved that the workers' responses were significantly correlated with health outcomes. In addition to this, Shikdar and Sawaqed (2003) pointed out that there was high correlation between performance indicators and health, facilities and environmental attributes. In other words, companies with higher health, facilities and environmental problems could face more performance related problems such as low productivity and high absenteeism. Employees with complaints of discomfort and dissatisfaction at study could have their productivity affected, result of their inability to perform their study properly (Leaman, 1995).

Light, noise, air quality and the thermal environment were considered factors that would influence the acceptability and performance on the occupants of premises (Olesen, 1995). Thermal comfort is influenced by air parameters (temperature, humidity, velocity and turbulence) and surfaces temperatures (walls, windows) and also by the type of human activity and clothing (Ismail et al., 2009a). Dua (1994) stated that lower emotional health is manifested as psychological distress, depression and anxiety, whereas lower social as disease, insomnia, headaches and infections. These health problems could lead to organizational symptoms such as job dissatisfaction, absenteeism and poor work quality. Irritated, sore eyes 
and throat, hoarseness, stuffy congested nose, excessive mental fatigue, headache and unusual tiredness were all signs of the negative workplace environmental conditions (Tarcan et al., 2004). The climate in Malaysia is well known to be tropical with its unfortunate combination of constantly high temperature and also very high humidity. The mean temperature is approximately $27^{\circ} \mathrm{C}$ while humidity can exceed values of $80 \%$ (Ismail et al., 2009b).

\section{MATERIALS AND METHODS}

In conducting this study, Fig. 1 shows the flow chart of the study those carried out.

From Fig. 1, this academic undertaking research initiated with identifies and choose four industry assembly automotive components in Malaysia as study site. The questionnaires consisted a set of Likert-type scales multiple choice items (Rodeghier, 1996). The questionnaires were distributed to the subjects individually. The questionnaires comprised 67 questions divided into five parts: (1) demographic, (2) work-discomfort level, (3) work satisfaction factors, (4) workstation design based on operator satisfaction factors, (5) operator satisfaction factors based on working area environment. However, this study will present on part five which is contribute to the environmental factors. Each worker was asked to complete the questionnaire in a room close to their work place. In the study questionnaire, researcher will distribute questionnaire form to operators to answer the questions relating to get data and statistics about personal information operator, comfort level of study work, factor influence operator satisfaction which is determine from the aspect of workstation design and station workplace environment.

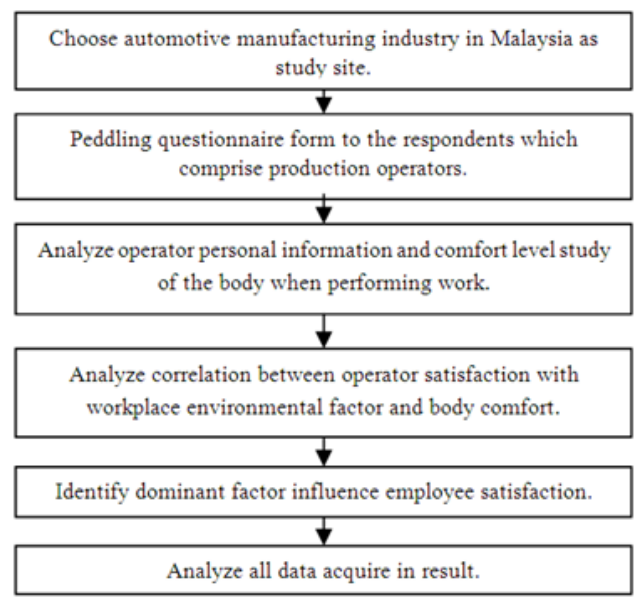

Fig. 1: Flow chart of the study
Later, personal information operator will be analyzed and frequency study of body pain operator during last working week bygones will study. In the determination of body pain, study will be conducted to determine part of the body that most pain during work and must give treatment.

Correlation among level of satisfaction operator while working with environmental factor workplace also determined. For correlation analysis, relation validity among two factors will be determined to get relationship Workplace environmental factor study conclude sweat heat, cold environment, light evidence, high level of noise, chemical radiation, heat conductivity and vibration tools when work. Apart from that, activities which are committed by operator while working also will be linked with body pain.

After analysis carried out, dominant factors influence satisfaction operator would be determined. All data will be analyzed to achieve objective of the study that prescribed.

\section{RESULTS AND DISCUSSION}

Demographic data: About 210 workers were included in the study. Data gathered would be classified as personal information operator with on the basis of sex, age, weight, height and other aspect. Table 1 shows the details analysis of respondent background. In this study, majority of respondents constitute male 93.8 and $6.2 \%$ were women. Base data acquired, height mode operator is $170-175 \mathrm{~cm}(27.1 \%)$ while body weight is $50-59 \mathrm{~kg}$ $(41.9 \%)$. From the questionnaire form was gathered, there were as many as $51.0 \%$ operator is not smoke.

Reliability measures: Questionnaire reliability was tested using Cronbach alpha $(\alpha)$ as shown in Table 2. Cronbach's alpha is derived from the average correlations of all the items on the scale (Rodeghier, 1996). Out of 4 reliability measures have been done, 3 had reliabilities above 0.7. One item had reliability measures of at least 0.4 . The results indicated that the reliability measures were high for musculoskeletal discomfort factors in four companies who involved in assembly work and repetitive tasks. Reliability measures for workstation design and environmental factors were also high with 0.805 and 0.760 .

Study of job satisfaction factor with environment of workplace: Questions on the part $\mathrm{E}$ focus on environment of workplace that contributes to level of satisfaction operator. There were 7 variable of environmental workplace will study and result from questionnaires will be described through graph to Table 4. 
Am. J. Applied Sci., 7 (4): 556-561, 2010

Table 1: Characteristics of the sample

\begin{tabular}{|c|c|c|c|c|}
\hline Characteristics & Category & Frequency & Percentage $(\%)$ & Mean \pm SD \\
\hline \multirow[t]{2}{*}{ Gender } & Male & 197 & 93.8 & $1.06 \pm 0.24$ \\
\hline & Female & 13 & 6.2 & \\
\hline \multirow[t]{5}{*}{ Age } & $<20$ & 4 & 1.9 & $2.31 \pm 0.62$ \\
\hline & $20-29$ & 149 & 71.0 & \\
\hline & $30-39$ & 45 & 21.4 & \\
\hline & $40-49$ & 11 & 5.2 & \\
\hline & $>50$ & 1 & 0.5 & \\
\hline \multirow[t]{5}{*}{ Height } & $<160 \mathrm{~cm}$ & 43 & 20.5 & $2.82 \pm 1.34$ \\
\hline & $160-165 \mathrm{~cm}$ & 56 & 26.7 & \\
\hline & $166-169 \mathrm{~cm}$ & 30 & 14.3 & \\
\hline & $170-175 \mathrm{~cm}$ & 57 & 27.1 & \\
\hline & $>175 \mathrm{~cm}$ & 24 & 11.4 & \\
\hline \multirow[t]{6}{*}{ Weight } & $<50 \mathrm{~kg}$ & 11 & 5.2 & $3.00 \pm 1.30$ \\
\hline & $50-59 \mathrm{~kg}$ & 88 & 41.9 & \\
\hline & $60-69 \mathrm{~kg}$ & 45 & 21.4 & \\
\hline & $70-79 \mathrm{~kg}$ & 35 & 16.7 & \\
\hline & $80-89 \mathrm{~kg}$ & 19 & 9.0 & \\
\hline & $>89 \mathrm{~kg}$ & 12 & 5.7 & \\
\hline \multirow[t]{4}{*}{ Working hour } & $8 \mathrm{~h}$ & 124 & 59.0 & $2.10 \pm 1.60$ \\
\hline & $9 \mathrm{~h}$ & 31 & 14.8 & \\
\hline & $10 \mathrm{~h}$ & 10 & 4.8 & \\
\hline & $>12 \mathrm{~h}$ & 45 & 21.4 & \\
\hline \multirow[t]{2}{*}{ Smoking } & Yes & 103 & 49.0 & $1.51 \pm 0.50$ \\
\hline & No & 107 & 51.0 & \\
\hline
\end{tabular}

Table 2: Reliability measures using Cronbach's $\alpha$ for tested factors

\begin{tabular}{ll}
\hline Tested factors & Alpha Cronbach $(\alpha)$ \\
\hline Musculoskeletal discomfort & 0.955 \\
Job satisfaction & 0.492 \\
Workstation design & 0.805 \\
Environmental factors & 0.760 \\
\hline
\end{tabular}

Analysis made to level job satisfaction through environment workplace show that there is $59.1 \%$ respondent agree and totally agree with the workplace situation they to be hot and cause body discomfort result sweat. As many as $15.9 \%$ respondent thinks that environmental circumstance workplace design is too cold and $31.1 \%$ respondent said light bright in workstation cause eye fatigue.

For variables from number 5, as many as $58.3 \%$ respondents feel their works are exposed to high level of noise. As many as $40.1 \%$ respondents agree and totally agree that they are exposed to radiation material disposed or chemical waste during work. Apart from that, $41.6 \%$ respondent thinks that workplace had no good heat conductivity and $33.3 \%$ respondent said working conditions cause vibration can hurt their body during using vibration tools.

Overall, job satisfaction percentage with the design workstation that maximum is $59.1 \%$ which is their condition of the workplace to be hot and cause body discomfort result sweat.

From the Table 3, we found that no have been links significant between each variable with the value $\rho$ for each variable is $<0.05$ except for relationship among variable 2 which is body discomfort result sweat, variable 5 which is high level of noise and variable 8 which is work vibration. Value $\rho$ which is less than 0.05 this reflect that have been links significant in among stated variable and interconnected with one another.

Although for relationship 3, 4, 6 and 7 own value that does not significant, this variable relationship with other variable for the environment workplace own value significant. Relationship own value significant that highest is body discomfort result sweat with job satisfaction with the value constant correlation, $r=0.0185$. Through the table stated, can be concluded that each variable those stated and test have pointed out that existence of association of each other with influence employee satisfaction.

As mentioned in the materials and methods, the demographic data revealed that height operator and body weight acquired normal because majority of respondents were male. Apart from that, summary from the Table 1 obviously shows that most operators are imbued tendency to work during $8 \mathrm{~h}$ each day where it is accordance with standard of working hour for operator.

Environment of workplace is the one of the factors affecting job satisfaction (Shikdar and Sawaqed, 2003). The correlation among variable of environmental factors with job satisfaction shows that relationship own value significant that highest are body discomfort result sweat with job satisfaction with the value constant correlation, $\mathrm{r}=0.0185$. 
Am. J. Applied Sci., 7 (4): 556-561, 2010

Table 3: Correlation among variable of environmental factors with job satisfaction

\begin{tabular}{|c|c|c|c|c|c|c|c|c|}
\hline Variable & & 1 & 2 & 3 & 4 & 5 & 6 & 7 \\
\hline \multirow[t]{2}{*}{ Job satisfaction } & $\mathrm{r}$ & 1.000 & & & & & & \\
\hline & $\rho$ & & & & & & & \\
\hline \multirow[t]{2}{*}{ Warmth sweating } & $\mathrm{r}$ & $0.185^{*}$ & 1.000 & & & & & \\
\hline & $\rho$ & 0.034 & & & & & & \\
\hline \multirow[t]{2}{*}{ Air conditional } & $\mathrm{r}$ & -0.079 & -0.075 & 1.000 & & & & \\
\hline & $\rho$ & 0.370 & 0.391 & & & & & \\
\hline \multirow[t]{2}{*}{ Bright light } & $\mathrm{r}$ & 0.074 & $0.281 * *$ & $0.203 *$ & 1.000 & & & \\
\hline & $\rho$ & 0.397 & 0.001 & 0.020 & & & & \\
\hline \multirow[t]{2}{*}{ High level noise } & $\mathrm{r}$ & $0.172 *$ & $0.441 * *$ & 0.140 & $0.356^{* *}$ & 1.000 & & \\
\hline & $\rho$ & 0.049 & 0.000 & 0.109 & 0.000 & & & \\
\hline \multirow[t]{2}{*}{ Radiation chemical } & $\mathrm{r}$ & -0.019 & $0.282 * *$ & $0.342 * *$ & $0.350 * *$ & $0.536^{* *}$ & 1.000 & \\
\hline & $\rho$ & 0.825 & 0.001 & 0.000 & 0.000 & 0.000 & & \\
\hline \multirow[t]{2}{*}{ Thermal conductivity } & $\mathrm{r}$ & -0.048 & $0.329 * *$ & $0.246^{* *}$ & $0.384 * *$ & $0.620^{* *}$ & $0.539 * *$ & 1.000 \\
\hline & $\rho$ & 0.588 & 0.000 & 0.004 & 0.000 & 0.000 & 0.000 & \\
\hline \multirow[t]{2}{*}{ Vibration } & $\mathrm{r}$ & $-0.173 *$ & 0.111 & $0.326 * *$ & $0.320^{* *}$ & $0.399 * *$ & $0.475 * *$ & $0.582 * *$ \\
\hline & $\rho$ & 0.048 & 0.207 & 0.000 & 0.000 & 0.000 & 0.000 & 000.000 \\
\hline
\end{tabular}

*: Correlation is significant at level 0.05 (2- tailed); **: Correlation is significant at level 0.01 (2- tailed)

Table 4: The Percentage of respondents' distribution on environment workplace that contribute to job satisfaction

\begin{tabular}{|c|c|c|c|c|c|c|c|c|}
\hline & $\mathrm{n}$ & $\mathrm{TD}(\%)$ & $\mathrm{D}(\%)$ & NS (\%) & $\mathrm{A}(\%)$ & TA $(\%)$ & Mean & SD \\
\hline $\begin{array}{l}\text { Warmth discomfort that related to } \\
\text { stickiness caused by sweating }\end{array}$ & 210 & 10.5 & 21.9 & 14.3 & 44.3 & 9.0 & 3.20 & 1.188 \\
\hline $\begin{array}{l}\text { Cold discomfort in air conditional room } \\
\text { related to environmental temperature }\end{array}$ & 210 & 19.0 & 32.4 & 32.9 & 13.8 & 1.9 & 2.47 & 1.013 \\
\hline Too bright light that leads to eye fatigue & 210 & 9.0 & 35.2 & 25.2 & 28.1 & 2.4 & 2.80 & 1.271 \\
\hline High level of noise & 210 & 13.8 & 13.3 & 14.8 & 43.3 & 14.8 & 3.32 & 1.271 \\
\hline $\begin{array}{l}\text { Expose to radioactive material disposed or } \\
\text { chemical material }\end{array}$ & 210 & 14.3 & 26.7 & 19.0 & 31.0 & 9.0 & 2.94 & 1.230 \\
\hline Bad thermal conductivity in the workstation & 210 & 11.4 & 21.9 & 26.2 & 32.9 & 7.6 & 3.03 & 1.147 \\
\hline Vibration that can cause injury to the body & 210 & 15.2 & 21.9 & 27.6 & 27.6 & 7.6 & 2.90 & 1.186 \\
\hline
\end{tabular}

TD: Totally disagree; D: Disagree; NS: Not Sure; A: Agree; TA: Totally agree

\section{CONCLUSION}

Industrial development seems to be going towards further globalization, distributed manufacturing and increased flexibility of production and continuous rapid changes are a rule. It is often the case with applied ergonomics projects, addressing specific work problems that researchers or consultants provide advice with little control or influence over how this will be implemented. This study also suggested that workstation area should be customized to fit the anthropometric specification of end users in order to prevent unnecessary ergonomic problems in the future. Furthermore, such a useful intervention program on reducing ergonomic hazards in the automotive manufacturing industries should also be a feasible ergonomic program in other industries, which shared similar difficulty in designing adjustable workstations for their workers with the automotive manufacturing industries. In these cases, the companies must have a particularly important role to play in establishing a balance between job satisfaction and working methods and the protection of employees' health, safety and other interests.

\section{ACKNOWLEDGEMENT}

The researchers would like to acknowledge the support given by University Kebangsaan Malaysia and ministry of higher education Malaysia for providing a research grant through modeling relationship of thermal comfort and productivity in Malaysia energy intensive industries, UKM-GUP-TK-08-16-059.

\section{REFERENCES}

Czubaj, C.A., 2002. School indoor air quality. J. Instruct. Psychol., 29: 317-321. http://findarticles.com/p/articles/mi_m0FCG/is_4_ 29/ai_95148395/?tag=content; col1

Das, B. and R.M. Grady, 1983. Industrial workplace layout and engineering anthropometry. Ergon. Workstat. Des., 26: 433-447. DOI: 10.1080/00140138308963360

De Croon, E., J. Sluiter, P.P. Kuijer and M. FringsDresen, 2005. The effect of office concepts on worker health and performance: A Systematic review of the literature. Ergonomics, 48: 119-134. DOI: $10.1080 / 00140130512331319409$ 
De Lange, A.H., T.W. Taris, M.A. Kompier, I.L. Houtman and P.M. Bongers, 2002. Effects of stable and changing demand-control histories on worker health. Scand. J. Work Environ. Health, 28: 94-108. PMID: 12019593

Dempsey, P.G., R.W. McGorry and N.V. O’Brien, 2004. The effects of work height, work piece orientation, gender and screwdriver type on productivity and wrist deviation. Int. J. Ind. Ergon.. 33: 339-346. DOI: 10.1016/j.ergon.2003.10.006

Dua, J.K., 1994. Job stressors and their effects on physical health, emotional health and job satisfaction in a university. J. Educ. Admin., 32: 59-78. DOI: 10.1108/09578239410051853

Ettner, S.L. and J.G. Grzywacz, 2001. Workers perceptions of how jobs affect health: A social ecological perspective. J. Occup. Health Psychol., 6: 101-131. DOI: 10.1037//1076-8998.6.2.101

Fisk, W.J. and A.H. Rosenfeld, 1997. Estimates of improved productivity and health from better indoor environments. Indoor Air, 7: 158-172. DOI: 10.1111/j.1600-0668.1997.t01-1-00002.x

Hoy, J., N. Mubarak, S. Nelson, M.S. de Landas, M. Magnusson and O. Okunribido, 2005. Whole body vibration and posture as risk factors for low back pain among forklift truck drives. J. Sound Vibrat., 284: 933-946. DOI: 10.1016/j.jsv.2004.07.020

Ismail, A.R., N. Jusoh, M.Z. Nuawi, B.M. Deros, N.K. Makhtar and M.N.A Rahman, 2009a. Assessment of thermal comfort at manual car body assembly workstation. World Acad. Sci. Eng. Technol., 54: 123-127. http://www.waset.org/journals/waset/v54/v5423.pdf

Ismail, A.R., N. Jusoh, K. Sopian, I.M.S. Usman, R. Zulkifli and M.N.A. Rahman, 2009b. Thermal comfort assessment: A study at Malaysia car manufacturer. Eur. J. Sci. Res., 27: 510-523.

Leaman, A., 1995. Dissatisfaction and office productivity. Facilities, 13: 13-19. DOI: 10.1108/02632779510078120.

Locke, E.A., 1976. The Nature and Causes of Job Satisfaction: Handbook of Industrial and Organizational Psychology, Dunnette, M.D. (Ed.). Rand McNally College Publishing Company, Chicago, pp: 1297-1350.
Marshall, L., E. Weir, A. Abelsohn and M.D. Sanborn, 2002. Identifying and managing adverse environmental health effects: 1 . Taking an exposure history. Can. Med. Assoc. J., 166: 1049-1055. PMID: 12002983

Matzler, K. and B. Renzl, 2006. Assessing asymmetric. Effects in the formation of employee satisfaction. Tourism Manage., 28: 1093-1103. DOI: 10.1016/j.tourman.2006.07.009

Olesen, B.W., 1995. International standards and the ergonomics of the thermal environment. Applied Ergon., 26: 293-302. DOI: 10.1016/00036870(95)00033-9

Parsons, K.C., 2000. Environmental ergonomics: A review of principles, methods and models. Applied Ergon., 31: 581-594. DOI: 10.1016/S00036870(00)00044-2

Rodeghier, M., 1996. Survey with Confidence: A Practical Guide to Survey Research Using SPSS. 1st Edn., SPSS Inc., Chicago, IL., pp: 178.

Mustafa, S.A., S. Kamaruddin, O. Othman and M. Mokhtar, 2009. The effect of ergonomics applications in work system on mental health of visual display terminal workers. Eur. J. Sci. Res., 31: 341-354.

Shikdar, A.A. and N.M. Sawaqed, 2003. Worker productivity and occupational health and safety issues in selected industries. Comput. Ind. Eng., 45: 563-572. DOI: 10.1016/S0360-8352(03)00074-3

Sluiter, J.K., E.M. de Croon, T.F. Meijman and M.H.W. Frings-Dresen, 2003. Need for recovery from work related fatigue and its role in the development and prediction of subjective health complaints. Occup. Environ. Med., 60: 62-70. DOI: 10.1136/oem.60.suppl_1.i62

Tarcan, E., E.S. Varol and M. Ates, 2004. A qualitative study of facilities and their environmental performance. Manage. Environ. Qual.: Int. J., 15: 154-173. DOI: 10.1108/14777830410523099

Yeow, P.H.P. and R.N. Sen, 2003. Quality productivity, occupational health and safety and cost effectiveness of ergonomic improvements in the test workstations of an electronic factory. Int. J. Ind. Ergon., 32: 147-163. DOI: 10.1016/S01698141(03)00051-9 